\title{
Filtrating Characteristics of Polymeric Porous Composites Composed of Polypropylene and Polyethylene
}

\author{
Byeng-Gil AHN, Ung-Soo CHOI, and Oh-Kwan KwON \\ Tribology Research Center, Korea Institute of Science and Technology, \\ P.O. BOX 131, Cheongryang, Seoul 130-650, Korea
}

(Received March 1, 1999)

\begin{abstract}
Polymeric porous composites consisting of polypropylene (PP) and polyethylene (PE) powder were prepared by continuous extrusion sintering method for use in air purification systems. SEM analysis showed that a composite polymeric porous structure made up of PP and PE was obtained. The morphologies consisted of PE melted and adhering to PP domains due to the lower melting temperature of PE than that of PP. The filtrating characteristics and mechanical properties of polymeric porous composite materials were investigated with variation in head die temperature of extruder, extrusion velocity, and the content and melt index of PE. The filtration efficiency increased with PE. However it increased by increasing the melt index of PE. The developed polymeric porous composites composed of PP and PE was suitable as the filtering element of air purification systems.

KEY WORDS Extrusion Sintering Method/Polymeric Porous Composites / Filtration Efficiency / Pressure Drop /
\end{abstract}

Recently, as the severity of the environmental pollution is confronted globally, there is increased attention regarding the manufacture and evaluation of the porous materials for filtering and cleaning hazardous wastes. ${ }^{1,2}$ Presently, typical manufacturing methods of porous materials based on polymers can be classified as molding sintering, ${ }^{3}$ pneumatic extrusion, ${ }^{4}$ and polymer foaming. ${ }^{5}$ Polymeric porous composite materials formed by various manufacturing methods show different filtering mechanisms depending on internal structures and shapes. ${ }^{6}$

The polymer extrusion sintering method developed in this research is a continuous manufacturing process where mixed powders of two polymers are extruded through a head die, which forms a porous composite material. Internal structures of the polymeric porous composites manufactured by the continuous extrusion sintering method show distinguishable characteristics in microstructure compared with those manufactured by other sintering methods. During continuous extrusion process, polymer particles undergo severe plastic deformation, and take complex shapes of porous structures. This morphological difference causes great difference in filtering characteristics of porous materials. In this study, morphological changes generated during the continuous extrusion of polymeric porous composite materials and corresponding differences of filtering characteristics were investigated.

The most distinctive features of polymeric porous composites manufactured by the extrusion sintering method are the continuous manufacturing process, controllable porosity and mean pore size with variation head die temperature of extruder, extrusion velocity, melt index and content of lower melting temperature polymer used as binder. Among these factors, material composition of two polymers with different melting temperatures is very important. Porosity and mean pore size greatly influence filtrating characteristics of porous composite materials. ${ }^{7}$

Mechanical properties of developed filtering composite materials made by continuous manufacturing process were observed with variation content of lower melting temperature polymer. Laboratory air filtering tester was used for filtrating characteristics test of polymeric porous composite materials, pressure drop and filtration efficiency. Filtrating characteristics of developed polymeric porous composites manufactured by continuous extrusion sintering method was closely related with mechanical properties of lower melting temperature polymer, which is used as binder.

In this research, polymeric porous composites consisting of two polymer powders with different melting temperatures were fabricated by new technology, continuous extrusion sintering. Morphological changes, mechanical properties, porosity, mean pore size, pressure drop and filtration efficiency were measured. Possibility of using the polymeric porous composites by continuous extrusion sintering method for filtering elements was examined.

\section{EXPERIMENTAL}

\section{Materials}

Polymeric porous composites fabricated by continuous extrusion sintering consist of two polymer powders with different melting temperatures. In this study, PP (polypropylene) powder was selected as main material, and small amount of PE (polyethylene) powder was added as binder. PP and PE were 300P manufactured by Tongyang Nylon Inc., Korea and R900 from Samsung Chemicals Inc., Korea, respectively. PP was used with $2 \mathrm{~g} / 10 \mathrm{~min}$ of melt index. But in case of PE, materials with 4 different melt indexes were selected. To reduce friction during continuous powder extrusion, a small amount of polypropylene wax (Lion Chemicals, L-C $502 \mathrm{~N}$, MW: 2000 , Korea) was added as friction reducer.

$\mathrm{PP}, \mathrm{PE}$, and PP waxes were mixed in ball mill for $24 \mathrm{~h}$ before continuous extrusion process. Polymeric porous materials were manufactured using these polymeric mixed powders with different melt index and content ratios of $\mathrm{PE}$, and variation head die tempera- 
Table I. Compositions of porous samples produced by extrusion sintering

\begin{tabular}{cc}
\hline & Composition $/$ mass $\%$ \\
\hline 1 & PP $85 \%+$ PE $7 \%+$ PP wax $8 \%$ \\
2 & PP $84 \%+$ PE $8 \%+$ PP wax $8 \%$ \\
3 & PP $83 \%+$ PE $9 \%+$ PP wax $8 \%$ \\
4 & PP $82 \%+$ PE $10 \%+$ PP wax $8 \%$ \\
5 & PP $81 \%+$ PE $11 \%+$ PP wax $8 \%$ \\
6 & PP $80 \%+$ PE $12 \%+$ PP wax $8 \%$ \\
7 & PP $79 \%+$ PE $13 \%+$ PP wax $8 \%$
\end{tabular}

Table II. Particle size distribution of dust

\begin{tabular}{cccccc}
\hline \multicolumn{3}{c}{ Particle size distribution/\% } & $\begin{array}{c}\text { Mean particle } \\
\text { size } / \mu \mathrm{m}\end{array}$ \\
\cline { 1 - 3 } $1-5 \mu \mathrm{m}$ & $6-8 \mu \mathrm{m}$ & $11-20 \mu \mathrm{m} 21-30 \mu \mathrm{m}$ above $31 \mu \mathrm{m}$ & \\
\hline 59.6 & 19.3 & 16.5 & 2.2 & 2.4 & 8.84 \\
\hline
\end{tabular}

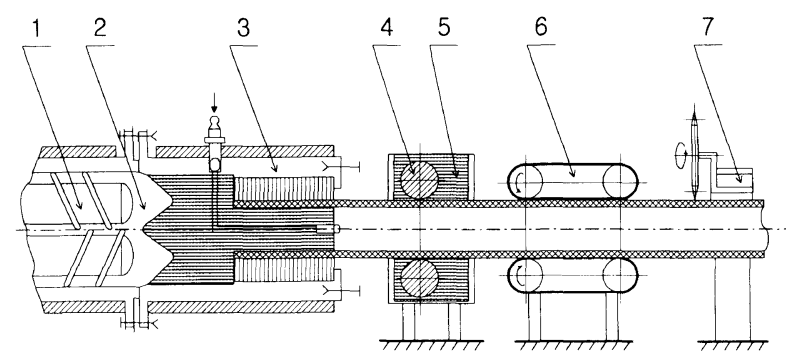

Figure 1. Continuous extrusion sintering. 1, double-screw extruder; 2, molding die inlet chamber; 3, molding head die; 4, shaping device; 5 , cooling bath; 6 , roller; 7 , cutter.

ture of extruder and extrusion velocity. Table I shows mixing ratios. Dust particles used for filtrating tests were powder number 15 defined in KS A 0090. A average powder size was $8.84 \mu \mathrm{m}$ and size distribution is shown in Table II.

\section{Experimental Facilities}

Twin screw extruder with cylinder diameter and length $60 \mathrm{~mm}$ and $1150 \mathrm{~mm}$, respectively, was used. Polymeric porous materials were obtained with variation head die temperature of extruder and extrusion velocity. The Figure 1 shows schematic diagram of continuous processing of polymeric porous composite materials. Under continuous extrusion, product and cross section shape are shown in Figures 2 and 3, respectively. Morphological changes during continuous extrusion sintering process were observed using SEM.

Filtrating test machine was constructed according to the KS standard (KS B 6141) type 3 for filtrating characteristics measurements of filtering materials, and is shown in Figure 4. Filtering area of materials for airfilter test was fixed as $0.10 \mathrm{~m}^{2}$. Using this laboratory air-filtrating test machine, pressure drop and filtration efficiency were measured.

Mean pore size of filtering materials was measured by bubble point tester (Porous Materials Inc., PMI Mercury Porosimeter, U.S.A.), and porosity was also measured using mercury impulse meter (Porous Materials Inc., PMI Capillary Flow Porometer, U.S.A.).

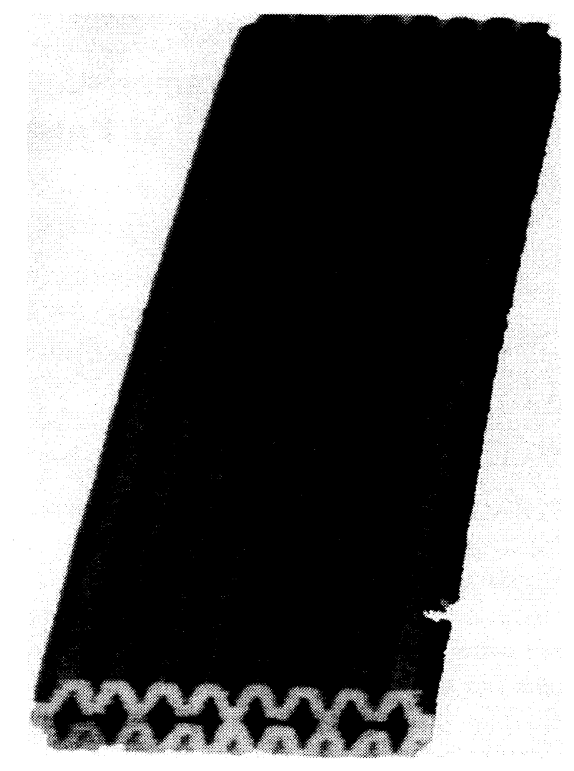

Figure 2. Porous polymeric composite sample manufactured by continuous extrusion sintering.

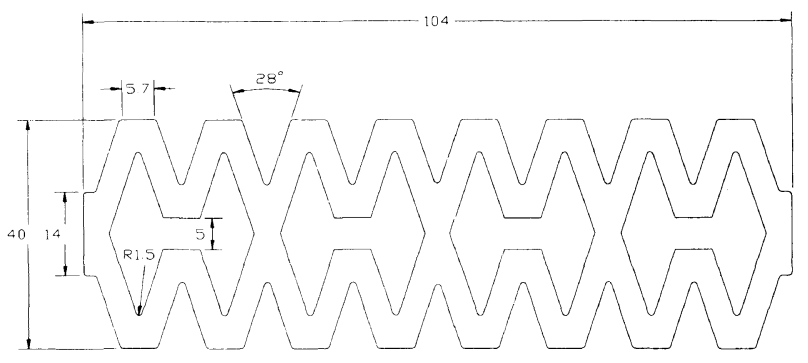

Figure 3. Cross-sectional schematic diagram of polymeric porous material.

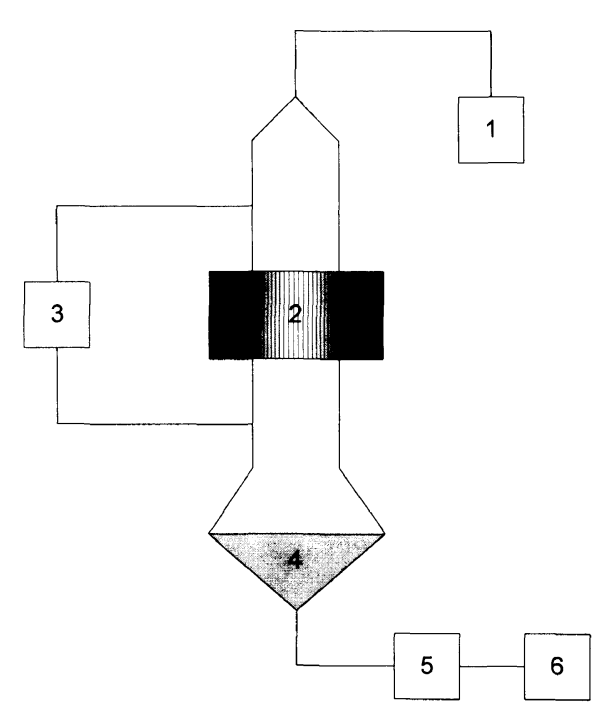

Figure 4. Schemaic diagram of air-filter tester. 1, dust generator; 2, filter element; 3 , digital manometer; 4 , absolute filter; 5, thermister; 6 , fan.

\section{Test Method}

One important factor that determine filtrating characteristics of filtering elements is pressure drop, and primary factor which determines pressure drop is closely related with mean pore size of filtering material. ${ }^{7}$ In filtrating characteristics test, pressure drop and filtra- 


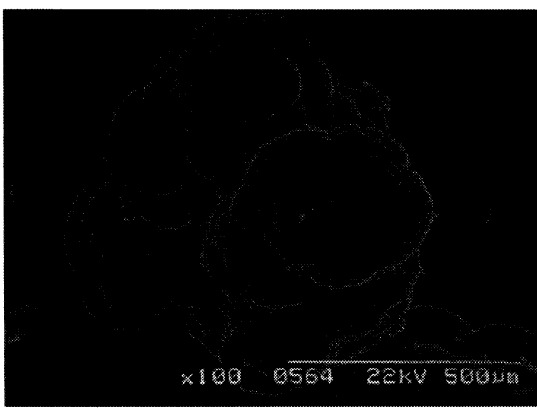

(a)

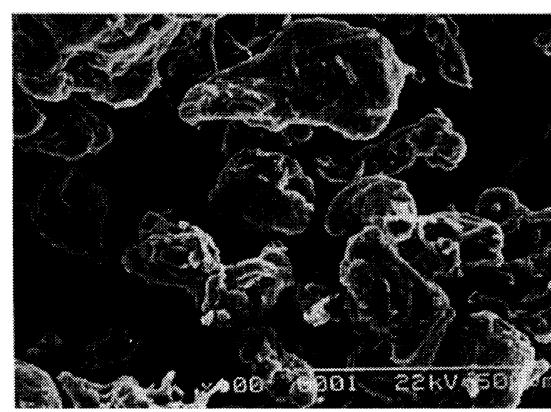

(b)

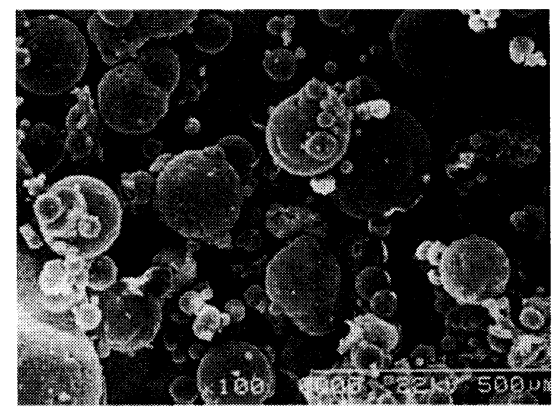

(c)

Figure 5. SEM photographs of raw materials: (a) PP; (b) PE; (c) PP wax.

tion efficiency of specimens with different content and melt index of PE added as binder were measured. Filtration efficiency was estimated using as follows,

$$
\eta(\%)=\frac{I-I^{\prime}}{I} \times 100
$$

where, $\eta$ : Filtration efficiency

I: Total mass of input powder

$I^{\prime}$ : Mass of powder that passed through filtering material

Feeding rate of contaminated powder was $0.5 \mathrm{~g} \mathrm{~min}^{-1}$. Total feeding quantity of powder was $4 \mathrm{~g}$. Average air velocity was fixed as $4.0 \mathrm{~m} \mathrm{~s}^{-1}$. Pressure drop was measured at the same time with filtration efficiency test, and estimated from pressure difference between front and back of filtering specimen.

\section{RESULTS AND DISCUSSION}

\section{Morphological Changes of Particles and Pore Structure}

Preliminary investigation prior to extrusion sintering was made of particle shape and polymer powders. Particle shapes of PP, PE, and PP wax were observed by SEM, and are shown in Figure 5. Average particle size of PP and PE was approximately $500 \mu \mathrm{m}$ and $120 \mu \mathrm{m}$ as seen in Figure 5, respectively.

SEM was used to observe surface morphology and fracture section surface of polymeric porous composites as seen in Figures 6 and 7. As content of PE is increased, mean pore size and porosity decreased under constant melt index of used PE, due to die swell at extrusion head die. The more melted PE, the more difficult die swell showed at extrusion head die. So, mean pore size and porosity of polymeric porous composites would be reduced with increasing melt index of PE under con- stant operating conditions. Because pore structure of polymeric porous composites manufactured by continuous sintering method was formed by melted PE and PP particles, content and melt index of $\mathrm{PE}$ determined pore structure.

Characteristic differences in microstructure between developed filter material made by continuous extrusion sintering method and molding sintering filter material are as follows. In case of continuous extrusion sintering filter materials, pore was generated at PP particles boundary which could be shown at Figure 6. This was due to die swelling of polymer material, especially PE. But in case of polymeric molding sintering filter material, pore was generated by partial adhesion of mixed polymer powder and formed with regular size hole between several polymer particles.

\section{Mechanical Properties}

Figure 8 shows variation of tensile strength $^{8}$ of filter specimen as a function of head die temperature of extrusion and content with variation extrusion velocity and melt index of PE, respectively. As content and melt index of PE increased, tensile strength of porous materials increased as seen in Figure 8(a). As melting quantity of $\mathrm{PE}$ used for binder increased under constant operating conditions of extruder, it may thus be difficult to die swell at head die and then tensile strength and density would increase.

From Figure 8(b), as head die temperature of extrusion increased, tensile strength also increased, but as extrusion velocity increased, tensile strength decreased.

As seen in Figures 8(a) and 8(b), mechanical properties of polymeric porous materials made by continuous extrusion sintering method were closely related to content and melt index of PE, head die temperature of extrusion and extrusion velocity under constant operating 


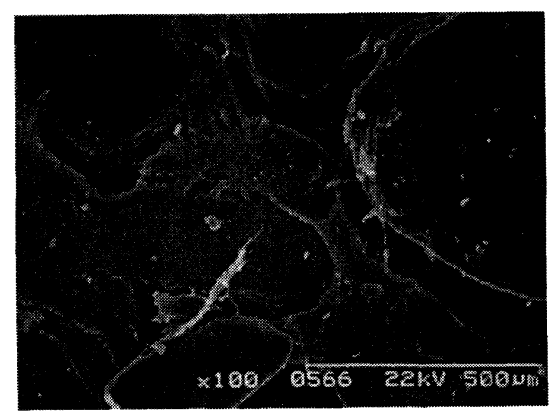

(a) PE 7 wt \%

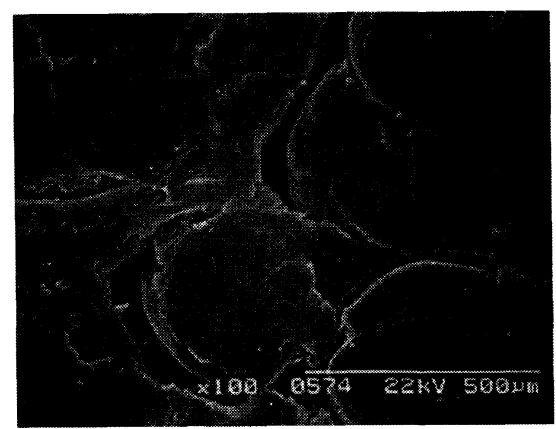

(c) PE $11 \mathrm{wt} \%$

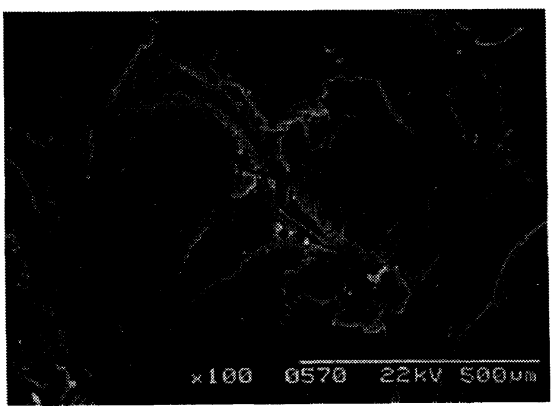

(b) PE 9 wt \%

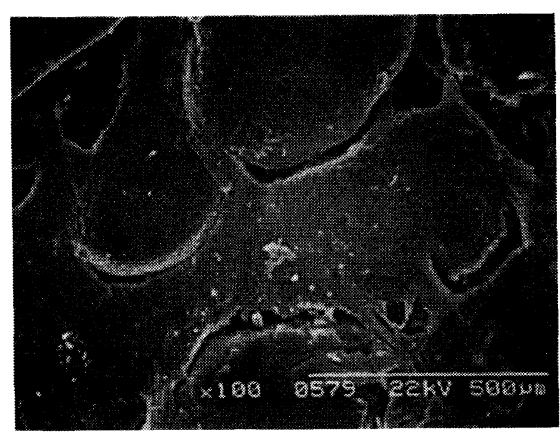

(d) PE 13 wt \%

Figure 6. SEM photographs of polymeric porous materials (surface part).

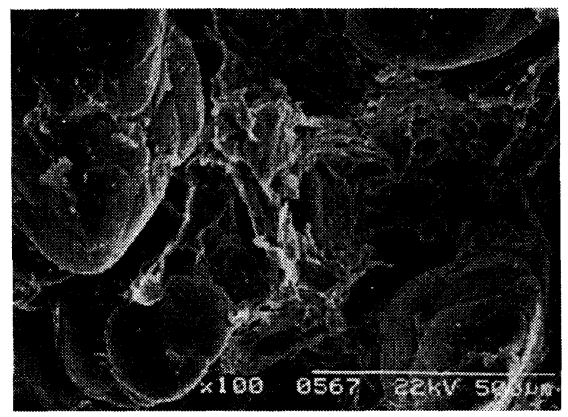

(a) PE 7 wt \%

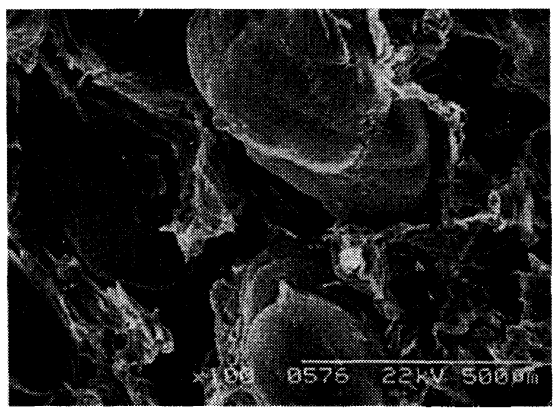

(c) PE 11 wt \%

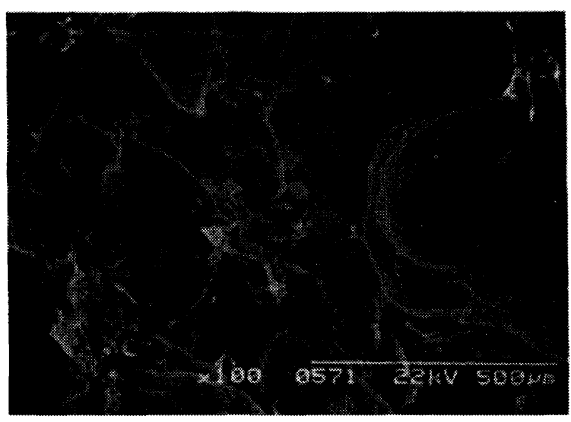

(b) PE 9 wt \%

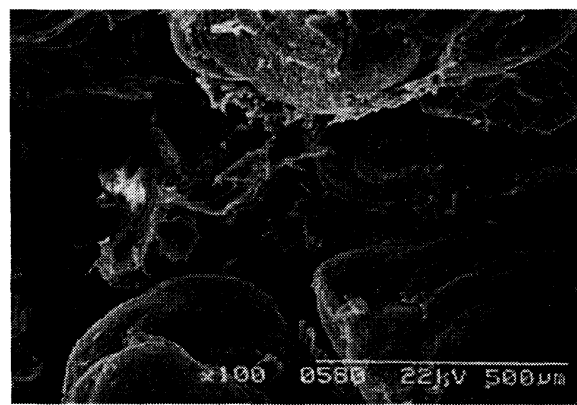

(d) PE 13 wt \%

Figure 7. SEM photographs of polymeric porous materials (fracture parts).

conditions of extruder.

\section{Mean Pore Size and Porosity}

Mean pore size and porosity were the most important factors for filtrating characteristics measured by mercury impulse meter and bubble point tester. ${ }^{7}$ Porosity and mean pore size was obtained with content shown Table
I and Figures 9 and 10. As content and melt index of PE were increased at constant head die temperature and extrusion velocity, porosity and mean pore size decreased. The reason may be that melted PE induces a difficult situation to enhancing die swell of polymer materials at extrusion head die.

From mean pore size and porosity of polymeric porous 


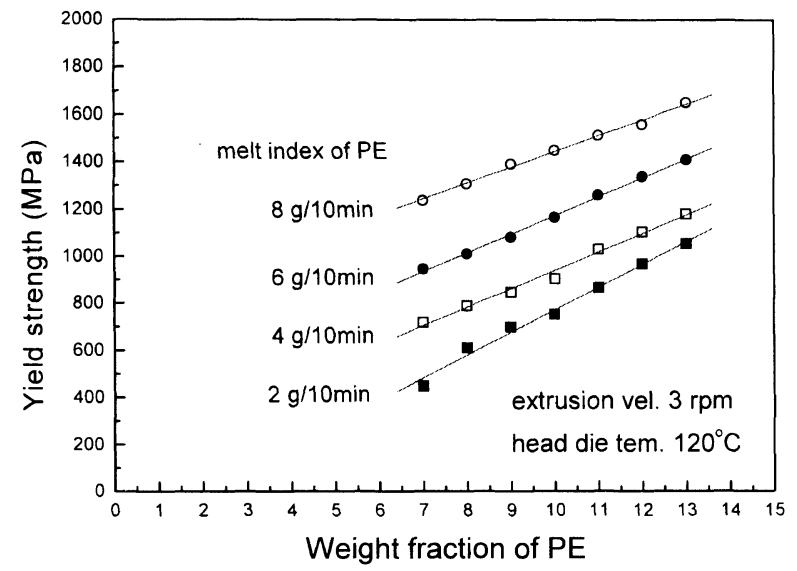

(a)

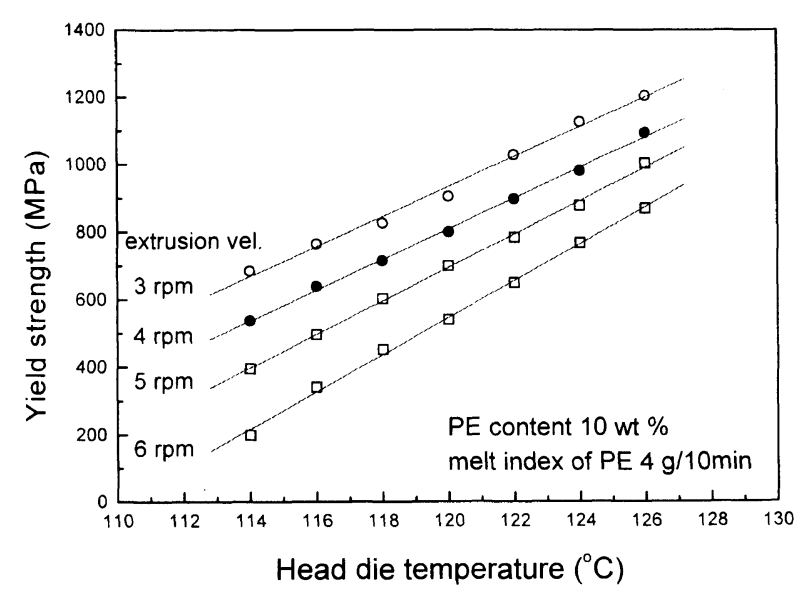

(b)

Figure 8. Ultimate tensile strength of polymeric porous materials. (a) yield strength $v s$. wt $\%$ of PE; (b) yield strength $v s$. head die temp.

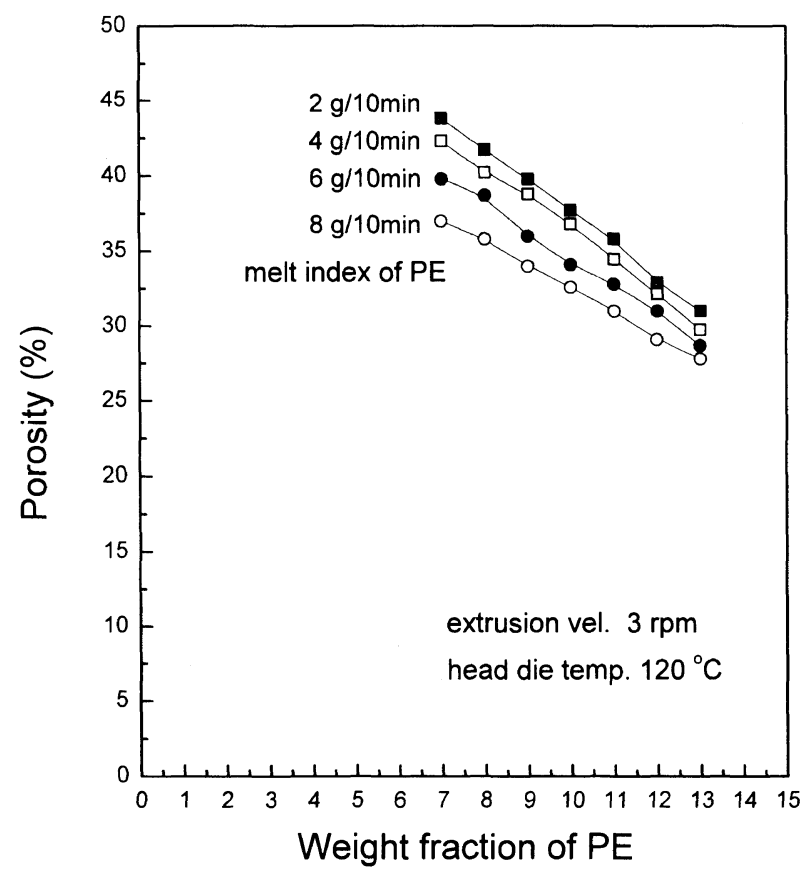

Figure 9. Correlation between porosity and weight fraction of PE.

composites results, porosity and mean pore size due to variation with $\mathrm{PE}$ content is in accord with observed morphological changes originating from PE content.

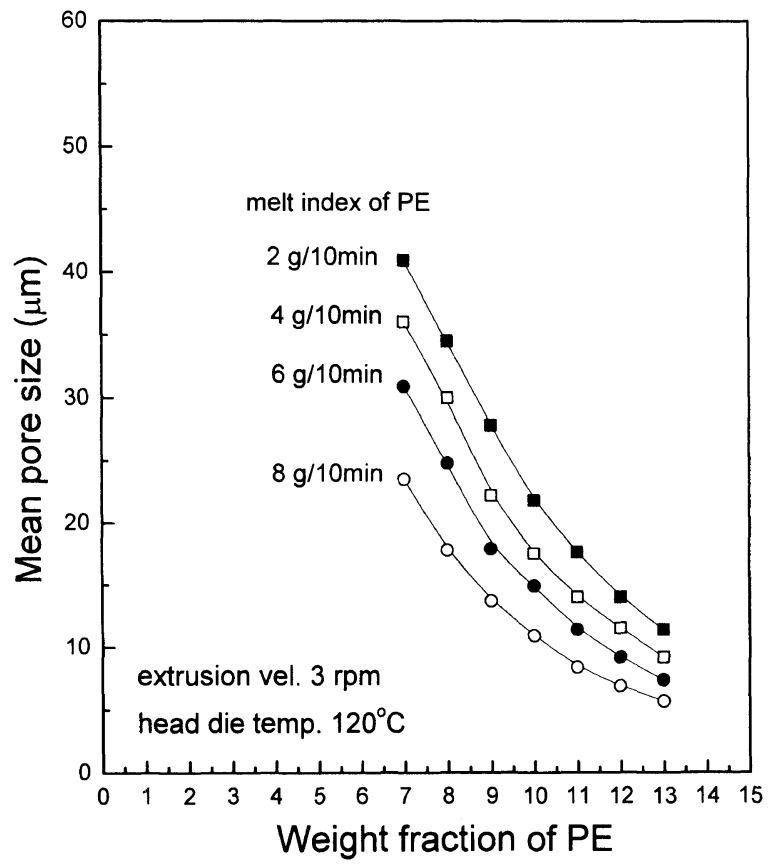

Figure 10. Correlation between mean pore size and fraction of PE.

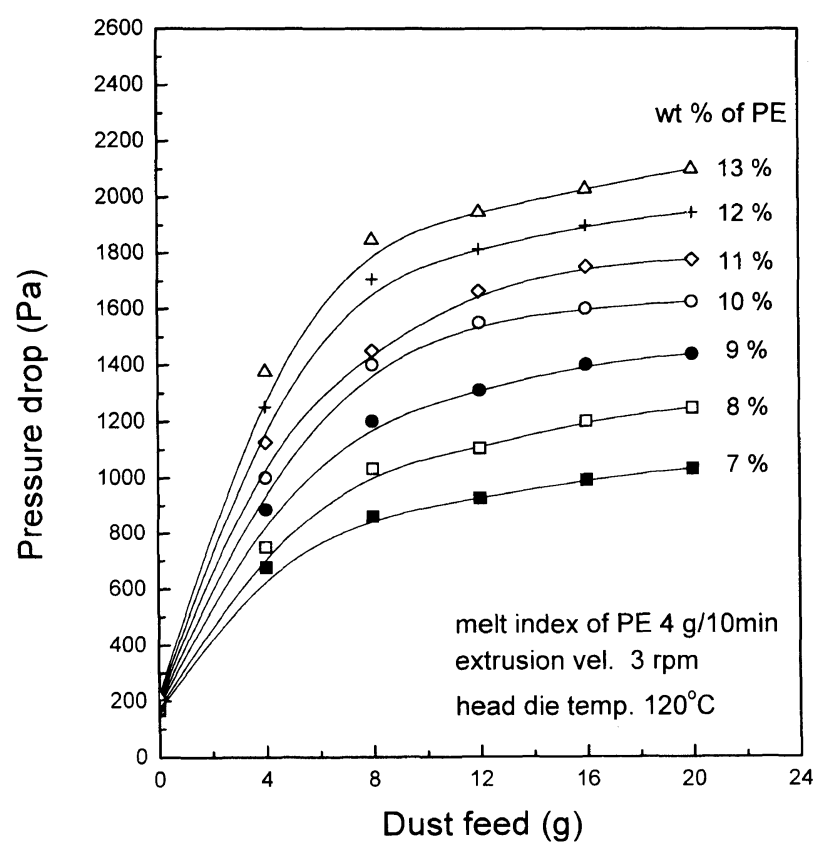

Figure 11. Correlation between pressure drop and dust feed.

\section{Pressure Drop}

Pressure drop of filtering materials is an important filtrating characteristic along with filtration efficiency. ${ }^{7}$ Pressure drop of polymeric porous materials with different content and melt index of PE was measured and is shown in Figure 11. As content of PE increased, pressure drop increased. This agrees well with the results in Figures 9 and 10. At initial stage of dust feeding on filtering test, pressure drop increased rapidly. But, at dust feeding over $8 \mathrm{~g}$, pressure drop increased loss. This seems related with clogging that dust particles closed pores. As content and melt index of PE increased, pressure drop increased, since porosity and mean pore size decreased. 


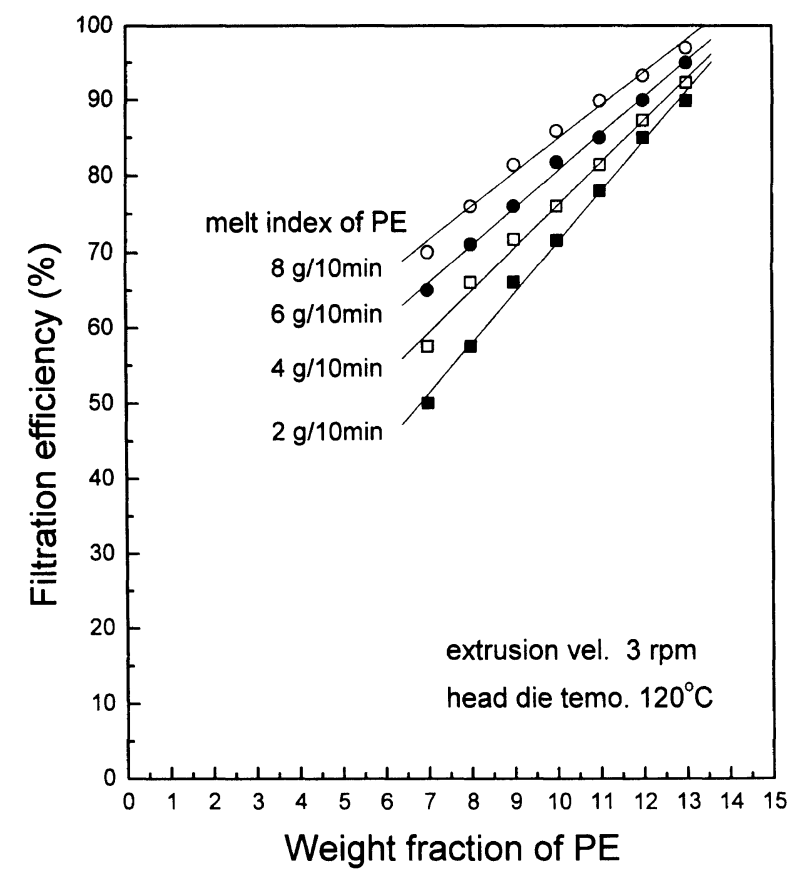

Figure 12. Filtration efficiency of polymeric porous materials on weight fraction of $\mathrm{PE}$.

\section{Filtration Efficiency}

Filtration efficiency varied with content and melt index of PE was calculated using the eq 1 under constant extrusion velocity $(3 \mathrm{rpm})$ and extrusion head die temperature $\left(120^{\circ} \mathrm{C}\right)$ as seen in Figure 12 . Filtration efficiency increased with PE quantity and melt index. Filtration efficiency may thus be affected by mean pore size and porosity of filtering materials. The maximum filtration efficiency of polymeric porous composites was $97 \%$. This shows that polymeric porous filter materials manufactured by continuous extrusion sintering has potential for use as filtering element for industrial dust collectors.

\section{CONCLUSIONS}

From observation of morphological changing of polymeric porous composites manufactured by continuous extrusion sintering, PP particles do not deform morphologically but PE particles undergo severe plastic deformation during extrusion sintering.

As content and melt index of PE increased under constant extrusion velocity and head die temperature, mean pore size and porosity of polymeric porous composites decreased, because increasing melted quantity of PE makes difficult for die swell of polymer materials. But, as content, melt index of PE and head die temperature increased, tensile strength of polymeric porous materials increased.

Pressure drop of polymeric porous materials increased, as content and melt index of PE increased. Mean pore size and porosity decrease resulting in increase of melted PE quantity. Filtrating characteristics of polymeric porous composites manufactured by continuous extrusion sintering process are closely related to head die temperature, extrusion velocity and content, melt index of low melting point polymer. These polymeric porous composites have the greatest potential for use as filtering elements for industrial dust collectors.

\section{REFERENCES}

1. L. C. Wadsworth and P. P. Tsai, "Advances in Filtration and Separation Technology," Vol. 12, St. Louis, MO, 1998, pp $216-232$.

2. K. Khalaf and K. L. Rubow, "Advances in Filtration and Separation Technology," Vol. 12, St. Louis, MO, 1988, pp $264-270$.

3. G. E. Herding and A. D. Walter, German Patent, 3413213, B01D (1984).

4. L. S. Pinchuk, V. A. Goldade, and Y. V. Gromyko, 6th World Filtration Congress, Nagoya, Japan, 940 (1993).

5. R. K. Gorodestskaya and L. I. Gracheva, Chemical Industry (Russia), No. 11, 13 (1991).

6. C. Dickenson, "Filter and Filtration Handbook," 3rd ed, Elsevier Science Publishers Ltd., Oxford, 1992, pp 50-59.

7. C. Dickenson, "Filter and Filtration Handbook," 3rd ed, Elsevier Science Publishers Ltd., Oxford, 1992, pp 19-49.

8. Standard Test Method for Tensile Properties of Polymer Matrix Composite Materials, ASTM D 3039. 